\title{
Single and Multi-Area Optimal Dispatch by Modified Salp Swarm Algorithm
}

\author{
Deepak Kumar Sharma ${ }^{1}$, Hari Mohan Dubey ${ }^{{ }^{2}}$, Manjaree Pandit ${ }^{3}$ \\ ${ }^{1,2,3}$ Department of Electrical Engineering, Madhav Institute of Technology \& Science, Gwalior-474005, INDIA \\ *Corresponding Author: +91-0751-2409348, E-mail: harimohandubeymits@ gmail.com
}

Received: 13 July 2018; Accepted: 31 October 2018; Published: 08 June 2020

\begin{abstract}
This paper presents modified salp swarm algorithm (MSSA) for solution of power system scheduling problems with diverse complexity level. Salp swarm algorithm (SSA) is a recently proposed efficient nature inspired (NI) optimization method inspired by foraging behaviour of salps found in deep ocean. SSA sometimes suffers to stagnation at local minima, to overcome this problem and enhancing searching capability by both exploration and exploitation MSSA is proposed in this paper. MSSA applied and tested on two types of problems. Type one is having five benchmark functions of diverse nature, whereas type two is related with real world problem of power system scheduling of a standard IEEE 114 bus system with 54 thermal units for (i) single area system, (ii) two area system and (iii) three area system. Finally Outcome of simulation results are validated with reported results by other method available in literature.
\end{abstract}

Index Terms - Salp swarm algorithm, leader and followers, benchmark functions, multi-area economic dispatch.

\section{INTRODUCTION}

During past few decades researchers had paid more attention to nature inspired optimization techniques for solution of different types of complex constrained real world problems. This may due to population based and involvement of random operator in almost all NI techniques, which helps to find out global or near global solution in single run for either nature of problem i.e. non-convex with multiple minima, discontinuous or nondifferentiable function [1-5]. These methods are inspired by natural process and broadly classified in five categories based on source of inspiration: evolution, swarm intelligence, human intelligence, ecology or physical science [6].

Economic dispatch (ED) is one of the important optimization issues in power system operation. Goal of ED is to allot the load demand among the committed power generating unit in most economical way while satisfying all the physical and operational constraints too[7,8]. Solution of different types of single area ED problems were presented using either classical solution/ NI based approach by various researchers [9-16]. Among
NI technique evolutionary programming (EP) [9], differential evolution (DE) [10], harmony search (HS) [11], biogeography based optimization (BBO) [12], artificial bee colony (ABC) [13], crow search algorithm (CSA) [14], hybrid PSO-GSA [15], flower pollination algorithm (FPA) [16], were applied to solve ED problems. A detailed survey of particle swarm optimization (PSO) and application to ED problem is presented in ref. [17].

Multi-area ED (MAED) is the expanded version of ED where each area having several power generating units connected with each other via tie line. Also transmission line (tie-lines) has various complexities related to costing, power wheeling and transfer capability. Each area has been controlled by independent system operator (ISO) and has its own pattern of load variation as well as power generation characteristics. There are also issues related to environmental pollution and global warming, minimization of harmful emission from power plant considered as other objective. The MAED problem has become much complex to solve due additional tie line capacity constraints along with the above mentioned operational constraints [18-29]. Considering new regulation for excessive generated greenhouse gases, a combination of MAED and constraints on emission has come in to picture called multi-objective multi-area economic dispatch (MOMAED). Solution of MOMAED using distinct NI approach can found in ref [30-34].

Reserve requirement is an important issue by the stability and reliability point of view for the power system network. Several technical papers have used MAED with reserve based constraints [35-38].

In this paper Modified version of recently proposed salp swarm algorithm is proposed to solve complex constrained MAED, problems of power system. This paper is organized in the following manners. Section II gives the review of the related work on MAED problem. Section III is presenting formulation of problem, concept behind SSA and its modification in section IV, description of problem and simulation results are in section $\mathrm{V}$ and finally concluding remark is presented in section VI.

\section{LITERATURE REVIEW}

Pioneer wok for related to MAED problem includes [18-20]. In past NI techniques as harmony search 
(HS)[21], artificial bee colony (ABC) [22], flower pollination algorithm (FPA)[23], evolutionary programming (EP)[24, 25], water wave optimization (WWO) [26], and teaching learning based optimization (TLBO)[27], were employed to solve MAED problems with different optional constraints. Attempt have been made for solution of two area problem with six generator unit system in ref [22],[23],[25-29], two area problem with four generator unit system in ref [29]. solution of MAED problem with three area system with three generator unit presented in ref [18] and with three area system with ten generator unit presented in ref.[22],[23],[25-30]. Whereas solution of MAED problem for four area with sixteen generating unit system are presented in [20, 21], [24], [29] and for four area forty generating unit system are presented in [22, 23], [25-29]. A comprehensive review of different metaheuristic and comparative analysis for solution of MAED problems are presented in ref [28].

Various solution approaches have been reported in literature that deal with solution of multi objective MAED problems using NI optimization. Solution of multi objective MAED problem with four area sixteen unit system found using $A B C$ [29], chemical reaction optimization (CRO) in ref [30] and solution of four area forty unit system were presented using $\mathrm{ABC}$ [29], symbiotic organism search (SOS) [31], and using hybrid shuffle frog leaping algorithm and PSO in ref [32]. Hybrid direct search method (HDSM) were applied to solve reserve constrained two area six unit MAED problem [33], and variants of DE and PSO [35]. Hybrid DE and PSO presented in [34] to solve MAED problem in electricity market prospective using four area with sixteen generating unit system. Impact of wind penetration with three area 52 generating unit system is investigated in ref. [36] and with three area 54 generating unit system in ref [37-38].

\section{PROBlem Formulation}

MAED problem is basically extension of ED problem that knit together more area in a single network connected through tie-lines [18]. The objective function of MAED problem combines two terms: (a) fuel cost associated with committed power generating units in all area (b) cost associated with power exchange between interconnected areas $[25,29]$.

Considering quadratic cost function of committed generator unit, total fuel cost $(F C)$ in all areas can be represented as [21, 22], [29]:

$$
F C=\sum_{i=1}^{N}\left\{\sum_{j=1}^{M} f_{i j}\left(P_{i j}\right)\right\}=\sum_{i=1}^{N}\left\{\sum_{j=1}^{M}\left(a_{i j} P_{i j}^{2}+b_{i j} P_{i j}+c_{i j}\right)\right\}
$$

Here $f_{i j}\left(P_{i j}\right)$ represents the fuel cost of $j^{\text {th }}$ power generator in area $i, a_{i j}, b_{i j}$ and $c_{i j}$ are the fuel cost coefficients, $N$ is number of area and $M$ represents the number of power generating unit in area $i$.
Active power transmission cost between areas (TC) can be represented as [22], [29]:

$$
T C=\sum_{j=1}^{M-1} \sum_{k=j+1}^{M} f_{j k} P t_{j k}
$$

$f_{j k}, P t_{j k}$ are the cost coefficient of power flow and power flow limit of tie line $j$ to $k$ respectively.

The objective function of MAED problem is to minimize the total costs $F_{t}^{\text {Cost }}$ and also has to satisfy all operational constraints associated with it [20, 21].

$$
F_{t}^{\text {Cost }}=\sum_{i=1}^{N}\left[\sum_{j=1}^{M} f_{i j}\left(P_{i j}\right)+T C\right]
$$

\section{A. Area power balance constraints}

In MAED problem the power balance constraints need to be satisfied for each area, neglecting transmission loss represented as [21,22]:

$$
\sum_{j=1}^{M} P_{i j}=P_{d i}+\sum_{k, k \neq i} P t_{i k}, i \in N
$$

Where $P_{d i}$ is the power demand of $i^{\text {th }}$ area, tie line power flow from $i^{\text {th }}$ to $k^{\text {th }}$ area is $P t_{i k}$.

\section{B. Generating limit constraints}

The real power output of each power generating unit must lie within their lower $\left(P_{i j}^{\min }\right)$ and upper $\left(P_{i j}^{\max }\right)$ limits, represented as [7-16], [22-29]:

$$
P_{i j}^{\min } \leq P_{i j} \leq P_{i j}^{\max } \quad i \in N \text { and } j \in M
$$

\section{Tie-line limit constraints}

The tie-line real power flows $\left(T_{i k}\right)$ from area $i$ to $k$ area should be between the maximum $\left(T_{i k}^{\max }\right)$ and minimum $\left(-T_{i k}^{\max }\right)$ limits of tie-line flow and it is represented as [21-23]:

$$
-T_{i k}^{\max } \leq T_{i k} \leq T_{i k}^{\max } .
$$

\section{SALP SWARM ALGORITHM}

Salps are barrel shaped free floating tunicate belongs to family of salpida. They move forward in deep water by pumping their bodies by propulsion. Salps search their food source in Deep Ocean in the form of swarm called swarm chain. Based on unique swarming and foraging behavior salp swarm algorithm (SSA) for optimization is recently developed by Mirjalili in 2017 [39].

During optimization the possible solution of problem is 
considered as salp chain. The salp chain broadly classified in two groups i.e. leader and followers. Basically salp located at beginning of chain called leader whereas remaining salps are called followers. Best salp (best solution) represents food source which is followed by remaining salps. During iterative process leader salp changes their position according to food source and followers follows the leader without trapping to local optima finally converges to global optima solution in reasonable time frame.

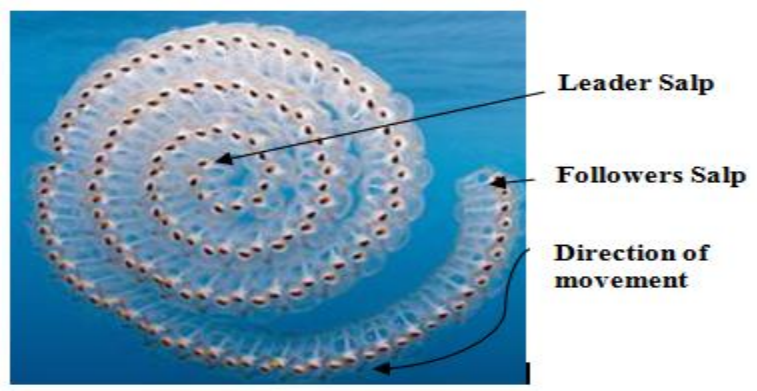

Fig.1. Salp Chain

In the mathematical model salps are initialized randomly with ' $\mathrm{m}$ ' dimension search space within lower and upper limits assuming ' $F$ ' as food source (target).

Leader salp updates their position as (7):

$$
\chi_{j}^{1}= \begin{cases}F_{j}+c_{1}\left(c_{2}\left(U b_{j}-L b_{j}\right)+L b_{j}\right) & c_{3} \geq 0.5 \\ F_{j}-c_{1}\left(c_{2}\left(U b_{j}-L b_{j}\right)+L b_{j}\right) & c_{3}<0.5\end{cases}
$$

Where, $X_{j}^{1}$ represents position of the first salp (leader) in the $j^{\text {th }}$ dimension search space. $F_{j}$ is the position of the food source in the $j^{\text {th }}$ dimension, $U b_{j}$ and $L b_{j}$ represents the upper, lower bound of the $j^{\text {th }}$ dimension respectively,

Eq. (7) shows that the leader only updates its position with respect to the food source.

The coefficient $c_{1}$ helps to make balance between exploration and exploitation and it is represented as (8):

$$
c_{1}=2 e^{-\left(\frac{4 l}{L}\right)^{2}}
$$

The parameter $C_{2}$ and $C_{3}$ are the random number between 0 and 1. Basically, they dictate whether the next position in $j^{\text {th }}$ dimension should be towards positive infinity or negative infinity as well as the step size.

The position of follower salps updated with the help of Newton's law of motion (9):

$$
x_{j}^{i}=\frac{1}{2} a t^{2}+v_{0} t \quad i \geq 2
$$

$$
\begin{gathered}
v=\frac{x-x_{0}}{t} \\
a=\frac{v_{\text {final }}}{v_{0}}
\end{gathered}
$$

With, $v_{0}=0$ the time in optimization process represents iteration and discrepancy between iteration considered as 1, analytically represented as (12):

$$
\chi_{j}^{i}=\frac{1}{2}\left(\chi_{j}^{i}+\chi_{j}^{i-1}\right) \quad i \geq 2
$$

\section{A. Modified salp swarm algorithm}

Modification in SSA is applied to improve exploration and exploitation capability by avoiding stagnation of standard SSA. The exploration capability is enhanced by introducing more randomness. The random mutation is applied as below.

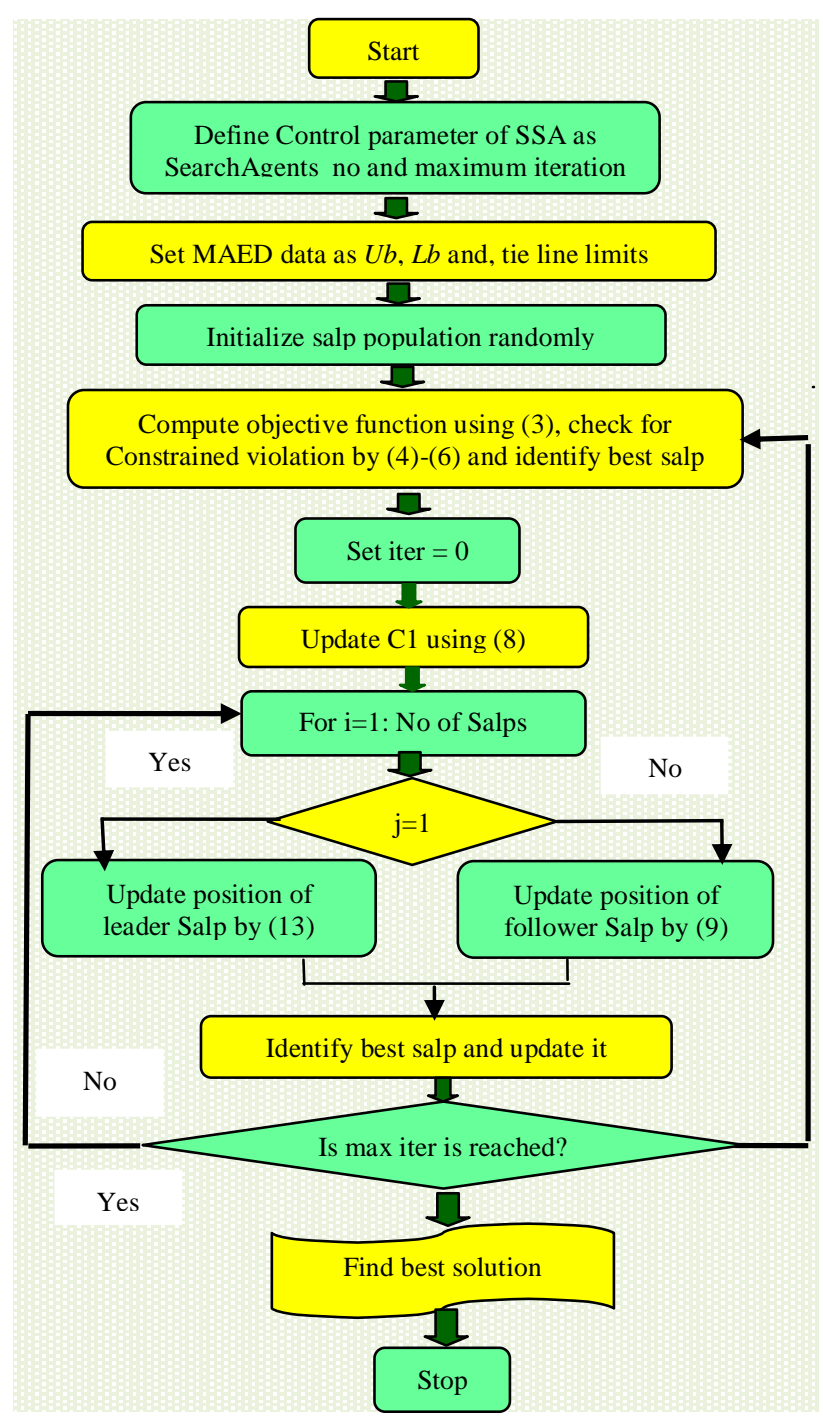

Fig.2. Flowchart for solution of MAED problems by MSSA 
Here also salps are randomly initialized within lower and upper limit similar to SSA.

But in MSSA Leader salp updates their position as (13):

$$
\chi_{j}^{1}= \begin{cases}F_{j}+c_{1}\left(c_{2}\left(U b_{j}-L b_{j}\right)+L b_{j}\right) & c_{3} \geq 0.7 \\ F_{j}-c_{1}\left(c_{2}\left(U b_{j}-L b_{j}\right)+L b_{j}\right) & c_{3}<0.7\end{cases}
$$

With $C_{2}$ are the random number between $(-1,1)$ and $C_{3}$ between $(0,1)$. The solution procedure of modified SSA for solving MAED problems is depicted using flowchart in Fig. 2.

\section{RESULTS AND DiSCUSSION}

Performance of MSSA is evaluated on two types of problems. First type of problem consists of standard mathematical benchmark functions and second type of problem is related with power system scheduling with three different test cases of single and multi area ED problem with different complexity level. MSSA have been implemented in MATLAB 13 and executed on
2.40GHz Intel core i3 processor with 4GB RAM. The description of test case and simulation results obtained by MSSA are presented as below. The search agent size for simulation is considered to be 100 .

\section{A. Test case 1}

It has standard mathematical benchmark functions comprise with unimodal, multimodal and composite modal. The descriptions of function and dimension of test cases along with its upper and lower limits considered for simulation analysis are presented in Table 1. Simulation analysis was carried out on these functions using MSSA over thirty repeated run considering large dimension. The outcomes of simulation results in terms of statistical parameter are tabulated in Table 2. The comparison of convergence characteristics of SSA and MSSA for all tested benchmark under consideration is also plotted in Fig.3 (a) to Fig.3 (e).

Statistical results and convergence curves listed below. It is clear that MSSA performs better as compared to SSA, PSO and GA.

Table 1. Description of benchmark test functions

\begin{tabular}{|l|}
\hline Function (Dimension $=\mathbf{3 0}$ ) \\
\hline$f_{1}=\sum_{i=1}^{m} x_{i}^{2},-100 \leq x_{i} \leq 100 \& f_{\min }=0$ \\
\hline$f_{2}=\sum_{i=1}^{m}\left|x_{i}\right|+\prod_{i=1}^{m}\left|x_{i}\right|,-10 \leq x_{i} \leq 10, f_{\min }=0$ \\
\hline$f_{3}=\sum_{i=1}^{m} i x_{i}^{4}+\operatorname{random}(0,1),-1.28 \leq x_{i} \leq 1.28, f_{\min }=0$ \\
$f_{4}=-20 e^{-0.02 \sqrt{m^{-1} \sum_{i=1}^{m} x_{i}^{2}}}-e^{m^{-1} \sum_{i=1}^{m} \cos \left(2 \pi x_{i}\right)}+20+e ;-32 \leq x_{i} \leq 32, f_{\min }=0$ \\
\hline$f_{5}=0.1\left[\sin ^{2}\left(3 \pi x_{1}\right)+\sum_{i=1}^{m}\left(x_{i}-1\right)^{2}\left\{1+\sin ^{2}\left(3 \pi x_{i}+1\right)+\left(x_{n}-1\right)^{2}\left\{1+\sin ^{2}\left(2 \pi x_{n}\right)\right\}\right\}\right]+\sum_{i=1}^{m} u\left(x_{i}, 5,100,4\right)$ \\
$-50 \leq x_{i} \leq 50, f_{\min }=0$
\end{tabular}

Table 2. Simulation results of benchmark functions

\begin{tabular}{|c|c|c|c|c|c|c|}
\hline \multicolumn{2}{|c|}{$f$} & $f_{1}$ & $f_{2}$ & $f_{3}$ & $f_{4}$ & $f_{5}$ \\
\hline \multirow{3}{*}{ MSSA } & Ave & $1.2235 \mathrm{e}-08$ & $7.8202 \mathrm{e}-06$ & 0.00202 & $9.7746 \mathrm{e}-06$ & $5.9602 \mathrm{e}-11$ \\
\cline { 2 - 7 } & Std & $1.8387 \mathrm{e}-09$ & $1.2522 \mathrm{e}-06$ & 0.0025 & $2.2038 \mathrm{e}-06$ & $2.8124 \mathrm{e}-11$ \\
\hline \multirow{2}{*}{ SSA[40] } & Ave & 0.000 & 0.2220 & 0.0028 & 0.0598 & 0.000 \\
\cline { 2 - 8 } & Std & 0.000 & 1.000 & 0.0070 & 0.5279 & 0.000 \\
\hline \multirow{2}{*}{ PSO[40] } & Ave & 0.2148 & 0.2858 & 0.0817 & 0.5917 & 0.0962 \\
\cline { 2 - 8 } & Std & 0.2663 & 0.0867 & 0.0635 & 0.9783 & 0.0911 \\
\hline \multirow{2}{*}{ GA[40] } & Ave & 0.3485 & 0.4172 & 0.3625 & 0.8864 & 0.0335 \\
\cline { 2 - 8 } & Std & 0.3714 & 0.0762 & 0.1503 & 0.2961 & 0.0438 \\
\hline
\end{tabular}
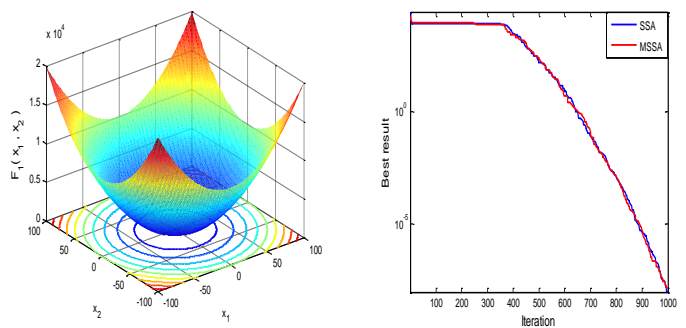

Fig.3(a). Sphere function
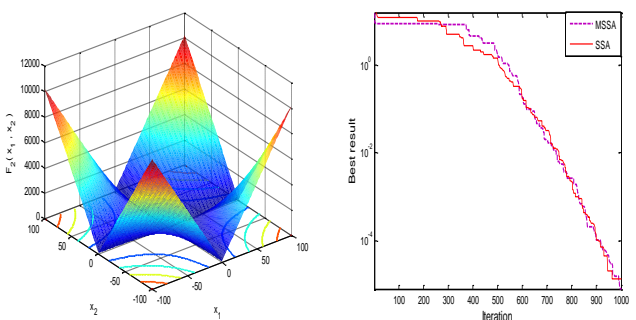

Fig.3(b). Schwefel function 

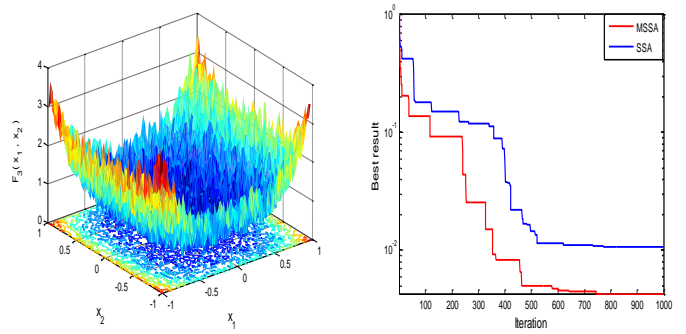

Fig.3(c). Quartic function
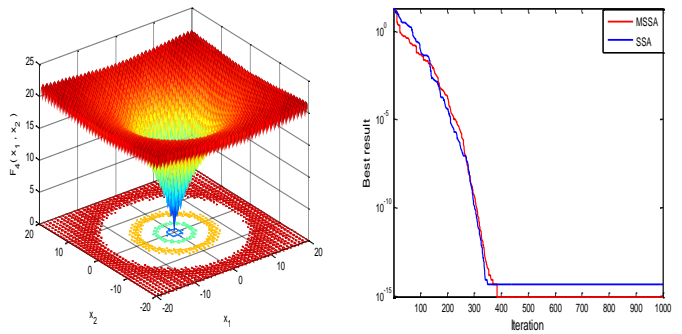

Fig.3(d). Ackley function
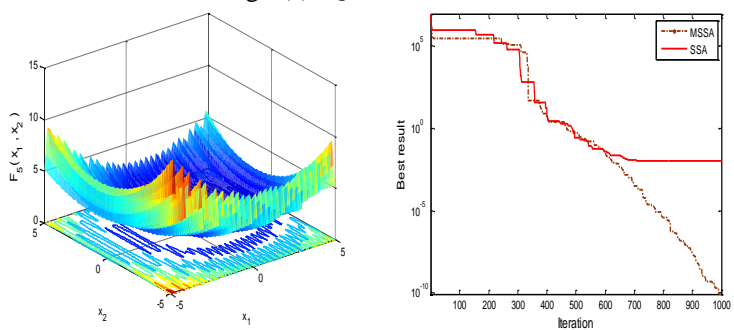

Fig.3(e). Levi function

Fig.3. Benchmark functions and their convergence curve

\section{B. Test case 2 (a)}

It is a practical IEEE 114 bus system having 54 thermal power generator units. The cost coefficient data along with upper and lower generation limit of generator are adopted as per ref [40]. The cost function is second order polynomial in nature. The total power demand is set at $4242 \mathrm{MW}$, Transmission loss is not considered here. The simulation results in terms of optimum generation scheduling obtained by SSA \& MSSA is plotted in Fig.4. The comparison of results made with other reported method is presented in Table 3. Here it is observed that the cost obtained by MSSA ( $\$ / \mathrm{hr} 22432.2447)$ is lower than SSA (\$/hr 22449.1679) and FPA [16]. Convergence curve of MSSA is found to be better than SSA as depicted in Fig.5.

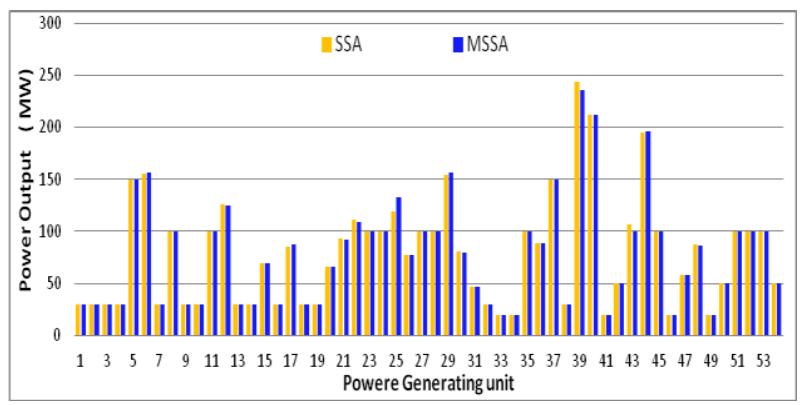

Fig.4. Optimum generation scheduling for 54 thermal unit system

Table 3. Comparison of simulation results for Test case 2 (a)

\begin{tabular}{|c|c|c|c|}
\hline \multirow{2}{*}{ Method } & \multicolumn{3}{|c|}{ Generation Cost $(\$ /$ hr $)$} \\
\cline { 2 - 4 } & Min Cost & Average Cost & Worst Cost \\
\hline FPA[16] & $22,432.3804$ & $22,483.1643$ & $22,896.9444$ \\
\hline MFPA[16] & $22,432.2307$ & $22,432.2801$ & $22,432.9153$ \\
\hline SSA & 22449.1679 & 22541.52722 & 22592.7308 \\
\hline MSSA & 22432.2447 & 22446.9487 & 22495.6752 \\
\hline
\end{tabular}

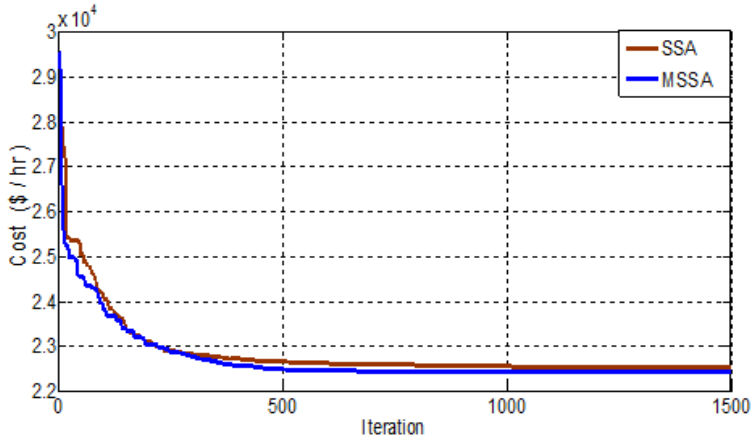

Fig.5. Convergence curve of SSA and MSSA for Test case 2(a)

\section{Test case $2(b)$}

It has two area systems with 54 thermal power generating units. The cost coefficient data are similar to above case and total load demand set at 4242MW. Each area with twenty seven power generating units shares the $40 \%$ power demand in area one and $60 \%$ in area two respectively. The tie-line power flow limit between area1 and area 2, from area 2 to area 1 is considered as 200MW.The network topology is shown in Fig.6 below. The simulation results in terms of optimum generation scheduling obtained by SSA \& MSSA are tabulated in Table 4 below, which fully satisfies the associated operational constraints. Here it is Also observed that the cost obtained by MSSA ( $\$ / \mathrm{hr} 22605.891931)$ is lower than SSA (\$/hr 22660.1069) and also MSSA is found to be better as depicted through cost convergence characteristics in Fig.7. 


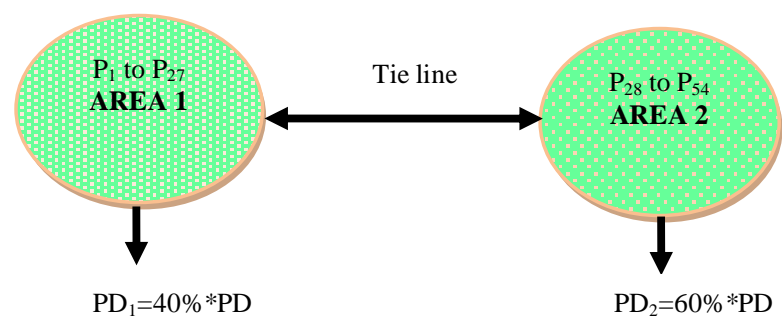

Fig.6. Two-area network with fifty four generating units

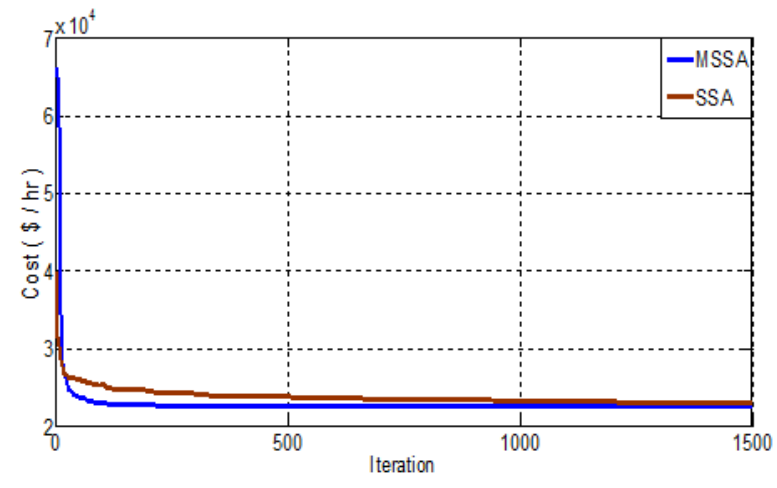

Fig.7. Convergence curve of SSA and MSSA for Test case 2 (b)

Table 4. Optimum generation scheduling for two area network Test case 2 (b)

\begin{tabular}{|c|c|c|c|c|c|}
\hline \multicolumn{3}{|c|}{ AREA1 $\left(\mathrm{PD}_{1}=40 \% * \mathrm{PD}\right)$} & \multicolumn{3}{|c|}{ AREA2 $\left(\mathrm{PD}_{2}=60 \% * \mathrm{PD}\right)$} \\
\hline unit & SSA & MSSA & unit & SSA & MSSA \\
\hline $\mathrm{P}_{1,1}$ & 29.6289 & 30 & $\mathrm{P}_{2,1}$ & 100 & 100 \\
\hline $\mathrm{P}_{1,2}$ & 29.9746 & 30 & $\mathrm{P}_{2,2}$ & 183.2269 & 172.5939 \\
\hline $\mathrm{P}_{1,3}$ & 29.3312 & 30 & $\mathrm{P}_{2,3}$ & 83.5606 & 84.2442 \\
\hline $\mathrm{P}_{1,4}$ & 29.6695 & 30 & $\mathrm{P}_{2,4}$ & 49.3162 & 50.8741 \\
\hline $\mathrm{P}_{1,5}$ & 152.1105 & 150 & $\mathrm{P}_{2,5}$ & 29.9581 & 30 \\
\hline $\mathrm{P}_{1,6}$ & 135.4819 & 135.3002 & $\mathrm{P}_{2,6}$ & 19.6857 & 20 \\
\hline $\mathrm{P}_{1,7}$ & 29.8818 & 30 & $\mathrm{P}_{2,7}$ & 19.7627 & 20 \\
\hline $\mathrm{P}_{1,8}$ & 93.7774 & 99.9976 & $\mathrm{P}_{2,8}$ & 98.4046 & 100 \\
\hline $\mathrm{P}_{1,9}$ & 29.8915 & 30 & $\mathrm{P}_{2,9}$ & 95.7134 & 96.5487 \\
\hline $\mathrm{P}_{1,10}$ & 29.3854 & 30 & $\mathrm{P}_{2,10}$ & 150 & 150 \\
\hline $\mathrm{P}_{1,11}$ & 100 & 100 & $\mathrm{P}_{2,11}$ & 29.9546 & 30 \\
\hline $\mathrm{P}_{1,12}$ & 109.864 & 107.5305 & $\mathrm{P}_{2,12}$ & 256.4547 & 253.9666 \\
\hline $\mathrm{P}_{1,13}$ & 29.5269 & 30 & $\mathrm{P}_{2,13}$ & 238.0034 & 231.3157 \\
\hline $\mathrm{P}_{1,14}$ & 29.5576 & 30 & $\mathrm{P}_{2,14}$ & 19.9958 & 20 \\
\hline $\mathrm{P}_{1,15}$ & 62.5678 & 62.0927 & $\mathrm{P}_{2,15}$ & 49.8045 & 50 \\
\hline $\mathrm{P}_{1,16}$ & 29.4705 & 30 & $\mathrm{P}_{2,16}$ & 100.1254 & 100.0001 \\
\hline $\mathrm{P}_{1,17}$ & 75.5007 & 74.9378 & $\mathrm{P}_{2,17}$ & 221.8563 & 215.2065 \\
\hline $\mathrm{P}_{1,18}$ & 29.6521 & 30 & $\mathrm{P}_{2,18}$ & 100.0002 & 100 \\
\hline $\mathrm{P}_{1,19}$ & 29.6448 & 30 & $\mathrm{P}_{2,19}$ & 19.8437 & 20 \\
\hline$P_{1,20}$ & 58.67 & 59.7689 & $\mathrm{P}_{2,20}$ & 56.5628 & 64.9687 \\
\hline $\mathrm{P}_{1,21}$ & 79.0068 & 83.9322 & $\mathrm{P}_{2,21}$ & 93.6883 & 96.0421 \\
\hline $\mathrm{P}_{1,22}$ & 106.0561 & 96.863 & $\mathrm{P}_{2,22}$ & 19.3746 & 20 \\
\hline $\mathrm{P}_{1,23}$ & 99.2221 & 100 & $\mathrm{P}_{2,23}$ & 49.6174 & 50 \\
\hline $\mathrm{P}_{1,24}$ & 99.8019 & 96.0321 & $\mathrm{P}_{2,24}$ & 84.4825 & 100 \\
\hline $\mathrm{P}_{1,25}$ & 129.6249 & 120.8426 & $\mathrm{P}_{2,25}$ & 99.3574 & 100 \\
\hline $\mathrm{P}_{1,26}$ & 66.7492 & 68.9418 & $\mathrm{P}_{2,26}$ & 99.9372 & 100 \\
\hline$P_{1,27}$ & 99.3111 & 100 & $\mathrm{P}_{2,27}$ & 49.9538 & 50 \\
\hline \multicolumn{4}{|c|}{$\mathrm{T}_{12}$} & 126.5592 & 119.4394 \\
\hline \multicolumn{4}{|c|}{ Cost $(\$ / \mathrm{hr})$} & 22660.1069 & 22605.891931 \\
\hline
\end{tabular}

\section{Test case 2(c)}

It is much complex test case with three area networks. The cost coefficient data and total load demand are similar to case 2(a). Here fifty four generating units are segregated in three areas having each area of eighteen units. Each area shares the power demand of $20 \%$ in area one, $30 \%$ in area two, $50 \%$ in area three respectively. The whole network topology considered in this case is shown below in Fig.8. Here also power flow limit between each area are considered as $200 \mathrm{MW}$ similar to test case 2 (b). With search agent size 100 over 1500 iteration, the simulation results in terms of optimum generation scheduling obtained by MSSA and SSA is listed in Table 5 and their convergence curves are presented in Fig. 9. Here also it is clearly observed that MSSA performs better for competitively large scale complex constrained test system. 


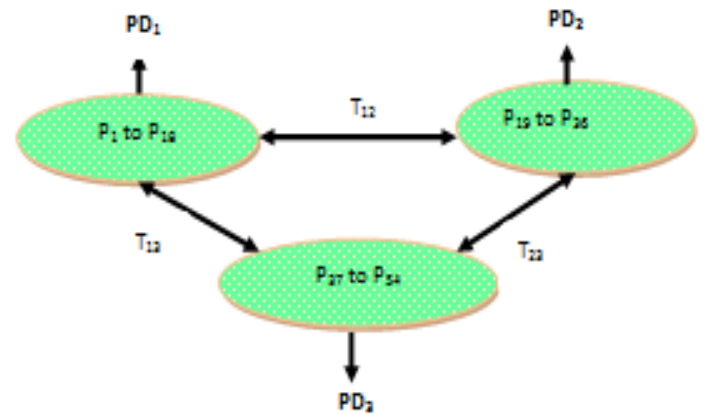

Fig.8. Three area topology with fifty four generating units

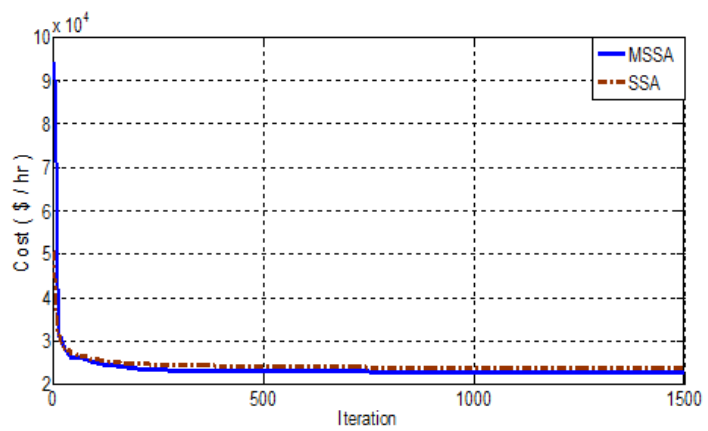

Fig.9. Convergence curve of SSA and MSSA for Test case 2 (c)

\section{E. Statistical Analysis of results}

Simulation analysis has been carried out over 30 repeated run with search agent size of 100 for each test case. For test case 1, having mathematical benchmarks with diverse nature, the statistical comparison of results are made in Table 2 with other methods. Here, it is clearly observed that MSSA performs better than SSA, PSO and GA with low standard deviation (S.D.) for almost all tested benchmarks. Also for practical constrained optimization problems listed as Test case 2(A) to 2(C), simulation results over 30 repeated run with search agent size of 100, Comparison of statistical results in terms of minimum cost, average cost and maximum cost obtained by SSA and MSSA is presented in Figure.10. Standard deviation (S.D.) and average computation time (second) considered by two computational methods for practical test cases are presented in Fig. 11.Here also it is clearly observed that MSSA attained minima with low SD and CPU time in all tested problems in consistent manner. It may be due to increase in diversification and avoidance of local minima during optimization.

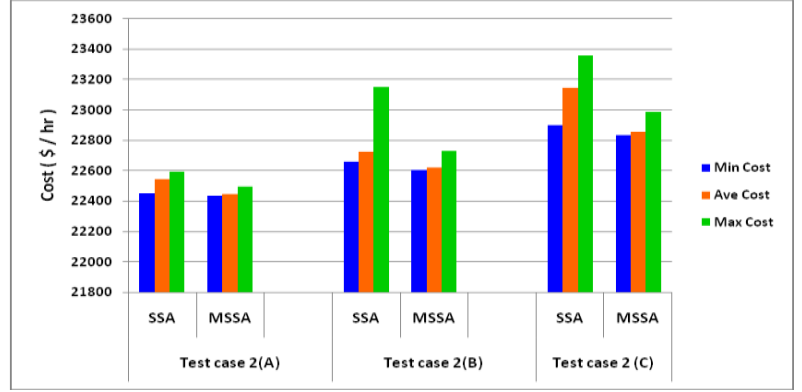

Fig.10. Comparison of Cost for practical Test cases

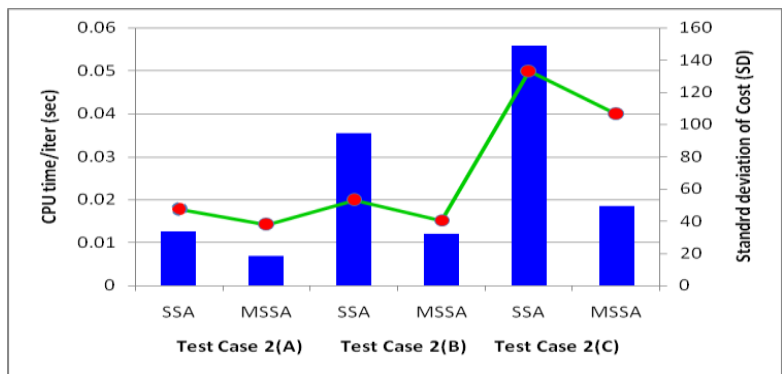

Fig.11. Comparison of Standard deviation and CPU time

\section{CONCLUSION}

In this paper modified Salp Swarm algorithm (MSSA) is proposed for solution of constrained optimization problems. Salps are basically marine organisms. They form long dense swarm during their foraging headed by leader salp. Salps updates their position based on position of leader and followers depending on availability of food source. Salp swarm algorithm (SSA) basically a nature inspired optimization approach that mimics the unique swarming and foraging behavior of salps in its analytical model that comprises of stochastic initialization, fitness calculation and updation similar to other NI optimization. In MSSA modification has been carried out in updation phase by introducing more randomness, which helps to strengthen the exploration and exploitation property of SSA and enhance the searching capability in better manner. MSSA and SSA is implemented and tested on two types of problems, type one is related with five mathematical benchmarks with different distinct nature and type two has three complex constrained optimization problems related to power system scheduling problems. To validate the simulation results comparison are also made with results available in recent literatures .Considering all simulation results obtained by SSA and MSSA we can say that MSSA has potential to offer superior solution with reasonable CPU time and it can be applied to solve other real world problem in efficient manner. 
Table 5. Optimum generation scheduling for three area network

Test case 2(c)

\begin{tabular}{|c|c|c|c|c|c|c|c|c|}
\hline \multicolumn{3}{|c|}{ AREA1 $\left(\mathrm{PD}_{1}=20 \% * \mathrm{PD}\right)$} & \multicolumn{3}{|c|}{ AREA1 $\left(\mathrm{PD}_{1}=30 \% * \mathrm{PD}\right)$} & \multicolumn{3}{|c|}{ AREA1 $\left(\mathrm{PD}_{1}=50 \% * \mathrm{PD}\right)$} \\
\hline unit & SSA & MSSA & unit & SSA & MSSA & unit & SSA & MSSA \\
\hline $\mathrm{P}_{1,1}$ & 28.4067 & 30 & $\mathrm{P}_{2,1}$ & 29.1216 & 30 & $\mathrm{P}_{3,1}$ & 150.0018 & 150 \\
\hline $\mathrm{P}_{1,2}$ & 24.9844 & 30 & $\mathrm{P}_{2,2}$ & 63.8576 & 62.6835 & $\mathrm{P}_{3,2}$ & 29.9202 & 30 \\
\hline $\mathrm{P}_{1,3}$ & 25.3081 & 30 & $\mathrm{P}_{2,3}$ & 98.3576 & 87.5147 & $\mathrm{P}_{3,3}$ & 263.6299 & 263.1022 \\
\hline $\mathrm{P}_{1,4}$ & 23.3214 & 30 & $\mathrm{P}_{2,4}$ & 114.8067 & 101.9755 & $\mathrm{P}_{3,4}$ & 247.4829 & 240.7523 \\
\hline $\mathrm{P}_{1,5}$ & 153.2199 & 150 & $\mathrm{P}_{2,5}$ & 98.9125 & 100 & $\mathrm{P}_{3,5}$ & 19.9992 & 20 \\
\hline $\mathrm{P}_{1,6}$ & 151.2317 & 132.7213 & $\mathrm{P}_{2,6}$ & 99.9593 & 100 & $\mathrm{P}_{3,6}$ & 49.7924 & 50 \\
\hline $\mathrm{P}_{1,7}$ & 29.999 & 30 & $\mathrm{P}_{2,7}$ & 121.3953 & 125.9702 & $\mathrm{P}_{3,7}$ & 111.114 & 100 \\
\hline $\mathrm{P}_{1,8}$ & 93.1698 & 95.3609 & $\mathrm{P}_{2,8}$ & 71.2182 & 72.4465 & $\mathrm{P}_{3,8}$ & 246.5447 & 225.2442 \\
\hline $\mathrm{P}_{1,9}$ & 29.6561 & 30 & $\mathrm{P}_{2,9}$ & 99.9157 & 100 & $\mathrm{P}_{3,9}$ & 100.0528 & 100 \\
\hline $\mathrm{P}_{1,10}$ & 28.7963 & 30 & $\mathrm{P}_{2,10}$ & 100.2046 & 100 & $\mathrm{P}_{3,10}$ & 19.9943 & 20 \\
\hline $\mathrm{P}_{1,11}$ & 100.0033 & 100 & $\mathrm{P}_{2,11}$ & 138.2129 & 147.6164 & $\mathrm{P}_{3,11}$ & 66.1769 & 69.1804 \\
\hline $\mathrm{P}_{1,12}$ & 126.2681 & 104.3482 & $\mathrm{P}_{2,12}$ & 87.22 & 80 & $\mathrm{P}_{3,12}$ & 85.2793 & 100 \\
\hline $\mathrm{P}_{1,13}$ & 9.4604 & 30 & $\mathrm{P}_{2,13}$ & 36.6612 & 43.6419 & $\mathrm{P}_{3,13}$ & 19.996 & 20 \\
\hline $\mathrm{P}_{1,14}$ & 29.7881 & 30 & $\mathrm{P}_{2,14}$ & 29.9935 & 30 & $\mathrm{P}_{3,14}$ & 48.1012 & 50 \\
\hline $\mathrm{P}_{1,15}$ & 52.0936 & 61.2984 & $\mathrm{P}_{2,15}$ & 15.1111 & 20 & $\mathrm{P}_{3,15}$ & 99.9801 & 100 \\
\hline $\mathrm{P}_{1,16}$ & 28.6801 & 30 & $\mathrm{P}_{2,16}$ & 19.9996 & 20 & $\mathrm{P}_{3,16}$ & 99.9063 & 100 \\
\hline $\mathrm{P}_{1,17}$ & 83.8162 & 74.6712 & $\mathrm{P}_{2,17}$ & 99.9828 & 100 & $\mathrm{P}_{3,17}$ & 99.9998 & 100 \\
\hline $\mathrm{P}_{1,18}$ & 29.842 & 30 & $\mathrm{P}_{2,18}$ & 64.995 & 83.4722 & $\mathrm{P}_{3,18}$ & 46.0578 & 50 \\
\hline \multicolumn{7}{|c|}{$\mathrm{T}_{12}$} & 0.0012 & 0.0000 \\
\hline \multicolumn{7}{|c|}{$\mathrm{T}_{13}$} & 199.644 & 200 \\
\hline \multicolumn{7}{|c|}{$\mathrm{T}_{23}$} & 117.3264 & 132.7209 \\
\hline \multicolumn{7}{|c|}{ Cost $(\$ / \mathrm{hr})$} & 23045.5133 & 22831.5761 \\
\hline
\end{tabular}

\section{REFERENCES}

[1] A. K. Kar, Bio Inspired Computing - A Review of Algorithms and Scope of Applications, Expert Systems with Applications, 2016, 59: 20-32.

[2] A. A. B. Baqais, A Multi-view Comparison of Various Metaheuristic and Soft Computing Algorithms, I.J. Mathematical Sciences and Computing, 2017, 1.3 (4):8-19.

[3] S. Roy, S. Biswas, S. S. Chaudhuri, Nature-Inspired Swarm Intelligence and Its Applications, I.J. Modern Education and Computer Science, 2014, 12: 55-65.

[4] Z. Qu, Q.Yang, Improved Particle Swarm Optimization for Constrained Optimization, I.J. Education and Management Engineering, 2012, 2: 21-28.

[5] R. C. Bansal, Optimization Methods for Electric Power Systems: An Overview, I. J. Emerging Electric Power Systems, 2005, 2(1):1-23.

[6] H.M. Dubey, M. Pandit, B. K. Panigrahi, An overview and comparative analysis of recent bio-inspired optimization techniques for wind integrated multiobjective power dispatch, Swarm and Evolutionary Computation, 2018, 38: 12-34.

[7] AJ Wood, BF Wollenberg, Power generation operation and control, $2^{\text {nd }}$ ed, Newyork, Wiley, 1996.

[8] B. H. Chowdhury, S, Rahrnan, A Review of recent advances in economic dispatch, IEEE Trans. On Power Systems, 1990, 5(4):1248 - 1259.

[9] N.Sinha, R. Chakrabarti, P. K. Chattopadhyay, Evolutionary Programming Techniques for Economic Load Dispatch, IEEE Trans Evol. Comput. 2003, 7(1):8393.

[10] N. Noman, H. Iba, Differential evolution for economic load dispatch problems, Electric Power Systems Research, 2008, 78(8):1322-1331.
[11] M. Fesanghary, M.M. Ardehali, A novel meta-heuristic optimization methodology for solving various types of economic dispatch problem, Energy, 2009, 34:757-766.

[12] A. Bhattacharya, P. K. Chattopadhyay, BiogeographyBased Optimization for Different Economic Load Dispatch Problems, IEEE Trans. Power Systems, 2010,25(2):1064-1077.

[13] B. Mahdad, K. Srairi, Solving Practical Economic Dispatch Problems Using Improved Artificial Bee Colony Method, I.J. Intelligent Systems and Applications, 2014, 07: 36-43.

[14] F. Mohammadi, H.Abdi, A modified crow search algorithm (MCSA) for solving economic load dispatch problem, Applied Soft Computing,2018, 71: 51-65.

[15] Hardiansyah, A Novel Hybrid PSO-GSA Method for Non-convex Economic Dispatch Problems, I.J. Information Engineering and Electronic Business, 2013, 5 : $1-9$.

[16] H.M. Dubey, M. Pandit, B.K. Panigrahi, A Biologically Inspired Modified Flower pollination algorithm for solving economic load dispatch problems in Modern Power system, Cogn Comp.2015,7(5):594-608.

[17] G. Abbas, J. Gu, U. Farooq,A. Raza, M.U. Asad, M. E. El-Hawary, Solution of an Economic Dispatch Problem Through Particle Swarm Optimization: A Detailed Survey - Part II, IEEE access, 2017,5:24426-24445.

[18] R.R. Shoults, S.K. Chang, S. Helmick, W.M. Grady, A practical approach to unit commitment, economic dispatch and savings allocation for multiple-area pool operation with import/export constraints, IEEE Trans. Power Appar. Syst., 1980, PAS-99, (2): 625-635.

[19] Z. Ouyang, S.M. Shahidehpour, Heuristic multi-area unit commitment with economic dispatch, IEE Proceedings C - Gener. Trans. Distri., 1991, 138(3):242 - 252.

[20] D. Streiffert, Multi-Area Economic Dispatch with Tie 
Line Constraints, IEEE Trans. Power Systems, 1995, 10(4): 1946-1951.

[21] V. R. Pandi, B. K. Panigrahi, M. K. Mallick, Improved Harmony Search for Economic Power Dispatch, IEEE $9^{\text {th }}$ Inter Conf on Hybrid Intelligent Systems, (HIS-2009), DOI: 10.1109/HIS.2009.294.

[22] M. Basu, Artificial bee colony optimization for multi-area economic dispatch, Energy, 2013, 49: 181-187.

[23] S. Vijayaraj, R. K. Santhi, Multi-Area Economic Dispatch Using Flower Pollination Algorithm, IEEE Inter Conf. ICEEOT2016, DOI: 10.1109/ICEEOT.2016.7755541.

[24] T. Jayabarathi, G. Sadasivam, V. Ramachandran, Evolutionary Programming-Based Multiarea Economic Dispatch with Tie Line Constraints, Electric Machines \& Power Systems, 2000,28(12): 1165-1176.

[25] M. Basu, Fast Convergence Evolutionary Programming for Multi-area Economic Dispatch, Electric Power Components and Systems, 2017. DOI: 10.1080/15325008.2017.1376234.

[26] L. Lakshminarasimman, M. Siva, R. Balamurugan, Water Wave Optimization Algorithm for Solving Multi-Area Economic Dispatch Problem, I. J. Computer Applications ,2017,167(5):19-27.

[27] M. Basu, Teaching learning-based optimization algorithm for multi-area economic dispatch, Energy, 2014, 68:21-28.

[28] J.K. Pattanaik, M. Basu, D.P. Dash, Review on application and comparison of metaheurisctic techniques to multi-area economic dispatch problem, protection and control of modern power systems,2017 2:17, https: //doi.org/ 10.1186 / s41601-017-0049-x.

[29] D. C. Secui, The chaotic global best artificial bee colony algorithm for the multi-area economic/emission dispatch, Energy, 2015, 93(2): 2518-2545.

[30] J. Q. Li, Q. K. Pan, P. Y. Duan, H. Y. Sang, and K. Z. Gao, Solving multi-area environmental/economic dispatch by Pareto-based chemical-reaction optimization algorithm, IEEE/CAA Journal of Automatica Sinica, 2017:1-11. DOI: $10.1109 /$ JAS.2017.7510454

[31] D. C. Secui, Large-scale multi-area economic/emission dispatch based on a new symbiotic organisms search algorithm, Energy conver. Manag. 2017, 154:.203-223.

[32] H. Narimani, S.E. Razavi, A. Azizivahed, E. Naderi, M. Fathi,M. H. Ataei, M. R. Narimani, A multi-objective framework for multi-area economic emission dispatch, Energy,2018, 154:126-142.

[33] C. L. Chen, Optimal generation and reserve dispatch in a multi area competitive market using a hybrid direct search method, Energy Conver. Manag. 2005, 46: 2856-2872.

[34] M. Ghasemi, J.Aghaei, E. Akbari, S. Ghavidel, L. Li, A differential evolution particle swarm optimizer for various types of multi-area economic dispatch problems, Energy ,2016, 107: 182-195.

[35] M. Pandit, L.Srivastava, M. Sharma, Performance comparison of enhanced PSO and DE variants for dynamic energy/reserve scheduling in multi-zone electricity market, Applied Soft Computing, 2015,37:619631.

[36] C. L. Chen, Z.Y. Chen, T.Y. Lee, Multi-area economic generation and reserve dispatch considering large-scale integration of wind power, I. J. Electrical Power \& Energy Systems, 2014,55:171-178.

[37] M. Doostizadeh, F. Aminifar, H. Lesani, H. Ghasemi, Multi-area market clearing in wind-integrated interconnected power systems: A fast parallel decentralized method, Energy Conversion and Management, 2016, 113:131-142.

[38] Z. Li, M. Shahidehpour, W.Wu, B.Zeng, B. Zhang, W.
Zheng, Decentralized Multiarea Robust Generation Unit and Tie-Line Scheduling under Wind Power Uncertainty, IEEE Trans. on Sustainable Energy,2015,6(4): 1377-1388

[39] S. Mirjalili, A. H. Gandomi, S. Z. Mirjalili, S. Saremi, H. Faris, S. M. Mirjalili, Salp Swarm Algorithm: A bioinspired optimizer for engineering design problems, Advances in Engineering Software, 2017, 114: 163-191.

[40] V.N. Dieu, P. Schegner, Real Power Dispatch on Large Scale Power Systems by Augmented Lagrange Hopfield Network, I. J. Energy Optimization and Engineering, 2012,1(1):19-38

\section{Authors' Profiles}

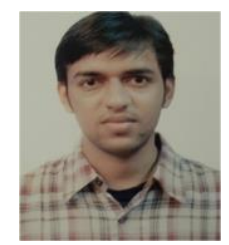

Deepak Kumar Sharma obtained his B.E degree in Electrical Engineering from Rewa Engineering College, Rewa, (India) in 2015. $\mathrm{He}$ is currently pursuing his M.E degree in Electrical Engineering (Industrial Systems and Drives), from M.I.T.S, Gwalior, (India). His areas of interest includes application of evolutionary computing and artificial intelligence applications to Power System.

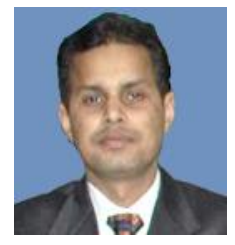

Hari Mohan Dubey obtained his M.E. degree in Electrical Engineering from Madhav Institute of Technology and Science, Gwalior in 2002 and Ph.D. degree from RGPV, Bhopal, (India), in 2017. He is with the Department of Electrical Engineering, M.I.T.S., Gwalior,(India). His areas of research include study of NI algorithms and their applications to different power system problems.

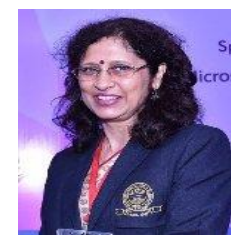

Manjaree Pandit received M.Tech. degree in Electrical Engineering from Maulana Azad College of Technology, Bhopal, India, in 1989 and the Ph.D. degree from Jiwaji University, Gwalior, India, in 2001. She is with the Department of Electrical Engineering, M.I.T.S., Gwalior. Her areas of interest are power system optimization and soft computing/evolutionary method ANN, and fuzzy neural applications to power system.

How to cite this paper: Deepak Kumar Sharma, Hari Mohan Dubey, Manjaree Pandit, "Single and Multi-Area Optimal Dispatch by Modified Salp Swarm Algorithm", International Journal of Intelligent Systems and Applications(IJISA), Vol.12, No.3, pp.18-26, 2020. DOI: 10.5815/ijisa.2020.03.03 